\title{
COMMISSION 20: POSITIONS AND MOTIONS OF MINOR PLANETS, COMETS AND SATELLITES (POSITIONS ET MOUVEMENTS DES PETITES PLANÈTES, DES COMÈTES ET DES SATELLITES)
}

\author{
Report of Meetings, 24, 25 and 27 August 1973
}

President: F. K. Edmondson.

SeCretary: B. G. Marsden.

\section{First Session}

The President opened the meeting by calling upon the Secretary to read notices of the deaths of two members since the last meeting: Yrjö Väisälä (1891-1971) and Michael Kamieński (1879-1973). The meeting stood in silence for a few moments in their memory.

A survey indicated that only about half of the members present had seen the report of the Commission, and discussion of the report was therefore postponed until the final session.

The meeting confirmed the proposals of L. Kresák for incoming President and B. G. Marsden for incoming Vice-President. The following members retired from the Commission: S. Böhme, G. M. Clemence, Y. Kozai and I. I. Shapiro. The following new members were elected: K. Aksnes, Yu. V. Batrakov, S. Ferraz-Mello, R. S. Harrington, A. R. Klemola, L. Kohoutek, B. A. Lindblad (co-opted since the 1970 meeting), R. E. McCrosky, B. Mintz Blanco, B. Morando, K. Tomita and J. G. Williams. The following were elected to the Organizing Committee for the next triennium: F. K. Edmondson, P. Herget, E. I. Kazimirchak-Polonskaya, B. Morando, W. H. Robertson, E. Roemer and J. Schubart. E. Roemer agreed to continue as Chairman of the Working Group on the Orbits and Ephemerides of Comets, and the other members of the Working Group were to be: M.P. Candy, E. I. Kazimirchak-Polonskaya, L. Kresák, B. G. Marsden, G. Sitarski and K. Tomita.

There was then some discussion on the desirability of appointing a Working Group devoted to the motions of satellites. Although the study of satellites is indicated in the name of the Commission, satellites have habitually been de-emphasized in relation to minor planets and comets. On the other hand, the reality of space missions to the outer planets had now made it very necessary to overhaul the theories of the motions of the satellites. The meeting agreed that the appointment of a Working Group on the Orbits and Ephemerides of Satellites would be very appropriate, and the following members were proposed for the group: B. Morando (Chairman), K. Aksnes, Yu. V. Batrakov, S. Ferraz-Mello, J. Kovalevsky, J. L. Sagnier and G. A. Wilkins; J. D. Mulholland and J. Lieske were co-opted as consulting members.

The possible co-sponsorship of two IAU Colloquia was then considered:

(1) 'An International Conference on the Natural Satellites of the Planets', to be held at Cornell University, Ithaca, New York, in June 1974. The President read sections of a letter received from J. A. Burns, the initial organizer of the conference. K. Aksnes was appointed the Commission's official representative on the Organizing Committee.

(2) 'Study of Comets', to be held at Goddard Space Flight Center, Greenbelt, Maryland, in October or November 1974. B. Donn was prepared to talk about this proposed colloquium at the third meeting of the Commission.

The Commission approved the earlier action by the President in asking the Finance Committee for continued support of the Minor Planet Center in the amount of $\$ 2000$ for the triennium 1974-76. (The Finance Committee increased the amount to $\$ 2200$.)

The Secretary read a resolution, prepared with the assistance of B. Morando and J. D. Mulholland, 
concerning the need for more intensive observations of the natural satellites of the outer planets, and after a brief discussion the resolution was adopted by the Commission. (See Resolution No. 3 at the end of this report.)

Z. Sekanina proposed that observers of positions of comets should be encouraged to supply information about the position angles and lengths of cometary tails. E. Roemer suggested that a more general proposal might be desirable, and further action was deferred until the final session.

The President mentioned an enquiry received from M. B. Protitch about the resolution passed at the General Assembly in Brighton concerning the difficulty of obtaining good quality photographic plates in reasonable quantities. No additional information was available on this subject.

In response to a question relayed from the Assistant General Secretary concerning the need for commissions to adopt 'rules', F. L. Whipple proposed that Commission 20 adopt a rule that there be no rules. This was seconded by $\mathbf{R}$. E. McCrosky and carried unanimously.

There was then some discussion on the suggestion by the Assistant General Secretary concerning future commission reports. After some discussion by the President, the Secretary, B. Morando, F. L. Whipple, E. Roemer and others, it was agreed that Commission 20 should take a strong position in favor of continued publication of the reports in the IAU Transactions. It was also suggested that the Executive Committee should make an effort to ensure that copies of the report of a commission would be available to members of that commission in advance of its first meeting.

Finally, the President briefly reported on the results of the joint meeting to discuss the future of the solar system commissions and on the subsequent deliberation by the Executive Committee. It was indicated that there would be little change in the activities of Commission 20, except that the physical studies of minor planets would be transferred to Commission 15 .

\section{Second Session}

This session, again chaired by the President, was devoted to scientific papers on minor planets. J. G. Williams gave an intensive review on the importance of continuing to observe minor planets and suggested priorities for future observing programs. B. G. Marsden gave an account of a joint investigation by $\mathrm{C}$. M. Bardwell of the Minor Planet Center and himself on the 'critical list'. E. Everhart then discussed the possibility of the existence of 'horseshoe orbits' in the Sun-Earth system and suggested that appropriate observations near the quadrature points could perhaps reveal objects moving in such orbits.

\section{Third Session}

This session was a joint meeting with Commissions 15 and 22 and was chaired by A. H. Delsemme, Vice-President of Commission 15.

E. Roemer brought up the question of the future of 'Comet Notes', and it was agreed that Icarus would be a suitable home for them if special arrangements could be made to cut down to no more than three months the time between submission of the manuscript and publication. The Bulletin of the American Astronomical Society was considered as an alternative if page charges could be vaaived.

B. Donn described the proposed conference on 'Study of Comets'.

Papers by F. L. Whipple and B. Donn then considered the desirability of launching space missions to comets; and B. G. Marsden gave an account of recent work by Z. Sekanina and himself on the nongravitational forces that affect the motions of comets.

\section{Fourth Session}

This session was organized by Commission 20's Working Group on Comets and was chaired by E. Roemer, B. Donn, E. Everhart and A. H. Delsemme all presented papers on the 'Origin of Comets', 
the last-named author restricting himself to the short-period comets. Z. Sekanina then discussed 'New Empirical Data on Distant Comets'; and T. Gehrels and C. Sagan reported on proposals for high-resolution imaging of cometary nuclei from spacecraft.

\section{Fifth Session}

Held under the chairmanship of B. Morando, this session was devoted to the study of orbits and positional observations of the natural satellites of the outer planets. The following papers were presented: J. Kovalevsky, 'The Present Status of the Theories of the Motions of the Satellites of the Planets'; G. A. Wilkins, 'Current Work in the United Kingdom on the Motions of the Satellites'; K. Aksnes, 'On the Need to Improve Satellite Ephemerides'; and S. Ferraz-Mello, 'An Analysis of Photographic Series of Observations of Jupiter's Galilean Satellites'.

\section{Sixth Session}

The final administrative session was held under the chairmanship of the President. M. P. Candy gave a brief description of the minor-planet observing program at the Perth Observatory, pointing out that the program is conducted in a manner somewhat similar to the suggestions by Williams and Marsden at the second session.

In response to the invitation for criticism of the Commission's report in IAU Trans. XVA, E. Everhart indicated that lines 11-13 on page 557 should read: "(1) Everhart reports that he has papers in press on 'Horseshoe and Trojan Orbits Associated with Jupiter and Saturn'; 'Examination of Several Ideas on Comet Origins'; 'Earth Horseshoe Orbits'; and 'A New Method of Integrating Orbits" "The report was then accepted.

It was agreed that Commission 20 should support Commission 15 in the proposal by B. Donn for a conference on 'Study of Comets' F. L. Whipple, E. Roemer and B. G. Marsden would represent Commission 20 on the Organizing Committee.

A rewording of $Z$. Sekanina's proposal, deferred from the first session, was discussed by E. Roemer, E. Everhart, F. L. Whipple and B. G. Marsden and adopted by the Cornmission (see Resolution No. 2 below). The Secretary then brought up a proposal, by J. G. Williams and himself concerning minor planets (Resolution No. 1), and after some discussion this too was adopted.

\section{Resolutions}

(1) Noting that the statistics of the minor planets are complete only to a mean opposition magnitude of about 15, and that many of the families of minor planets therefore contain very few known members;

recognizing that certain classes of unusual minor planets (Apollo and Amor objects, objects with high orbital inclinations, objects whose motions are commensurable with that of Jupiter, etc.) appear to be underrepresented among the numbered objects and in minor-planet surveys;

Commission 20 urges observers to search for and to report unusual objects.

The Commission points out that it is still scientifically useful to discover and follow up main-belt objects.

(2) Observers of positions of comets are urged also to note and report physical characteristics whenever possible. Of particular interest are:

Brightness, distinguishing between 'total' $\left(m_{1}\right)$ and 'nuclear' $\left(m_{2}\right)$ magnitudes;

Dimensions and any distinctive properties of the coma, such as asymmetries or other unusual brightness distribution;

Length, orientation and structural characteristics of the tail, if any.

Notice of unusual activity should be communicated by telegram or airmail letter to the IAU Central Telegram Bureau.

(3) Noting that the ephemerides of most of the natural satellites are based on observations made 
long ago, and that efforts to improve the ephemerides have been hampered by the paucity of recent observations;

acknowledging that much higher accuracy in the ephemerides of these objects will soon be required, particularly for the exploration of the outer solar system by spacecraft;

Commission 20 urges that a reasonable amount of telescope time be made available for observations useful for the improvement of satellite ephemerides. (This resolution was endorsed by Commission 4.) 